\title{
NEXT GENERATION LASER OFF-GAS ANALYSIS AT SDI, BUTLER, IN USA*
}

\author{
Andrew Spencer ${ }^{1}$ \\ Igor Todorovic ${ }^{2}$ \\ Armando Vazquez ${ }^{2}$
}

\begin{abstract}
Steel Dynamics Inc. (SDI) and Tenova Goodfellow Inc. (TGI) have successfully commissioned the first hybrid extractive/laser system for continuous and full spectrum analysis (CO, $\mathrm{CO} 2, \mathrm{O} 2, \mathrm{H} 2$ and $\mathrm{H} 2 \mathrm{O}$ vapor) on two twin shell furnaces at Butler, Indiana. NextGen® technology using off-gas analysis as a main tool for EAF practice optimization is a proven effective method for improving plant productivity. Significant benefits attributed to the NextGen® system are operational cost reductions through the use of real-time dynamic control of chemical energy and improved environmental conditions through reduced GHG emissions. Additionally, the implementation of Tenova's Water Leak Detection Technology ${ }^{\circledR}$ has shown results as an effective tool for operators to identify in real-time the presence of water during both reducing and oxidizing conditions. This paper will include project details, trials and results and will also outline the latest hardware developments and multipoint capabilities
\end{abstract}

Keywords: Optimization, post-combustion off-gas analysis, EAF, NextGen

Steel Dynamics Inc., Flat Roll Division, 4500 County Road 59, Butler, IN 46721 USA

Tenova Goodfellow Inc., \#200-6711 Mississauga Road, Mississauga, ON L5N 2W3 Canada 


\section{INTRODUCTION}

Steel Dynamics Inc. ("SDI”) - Flat Roll Division located in Butler, Indiana fitted their two twin shell EAF furnaces with Tenova's NextGen ${ }^{\circledR}$ hybrid extractive/laser off-gas analysis technology. SDI Butler was the first steel company worldwide to install the NextGen ${ }^{\circledR}$ technology in North America. Tenova's NextGen ${ }^{\circledR}$ technology incorporates the main advantages of extractive and laser off-gas analysis technology. It incorporates a "State of the Art - multipoint" optical analyzer which is designed to be located in the shop's Control Pulpit or control room. A single NextGen ${ }^{\circledR}$ multipoint analyzer can continuously analyze off-gas composition from up to 4 off-gas sampling locations, which means a steel shop can be equipped with a single central analyzer to cover multiple needs; this unit is connected by fiber optic/coax cables to remote compact sampling stations which contain a high volume pump to continuously \& reliably extract an off-gas sample from the near-by probe located in the fume duct. The off-gas is continuously filtered to remove particulate and then analyzed to provide a full spectrum analysis $\left(\mathrm{CO}, \mathrm{CO}_{2}, \mathrm{O}_{2}, \mathrm{H}_{2}, \mathrm{H}_{2} \mathrm{O}\right.$ vapor \& $\mathrm{N}_{2}$ by difference) using laser technology and other analytical sensors as needed. The sampling stations are designed to be compact so that they can be mounted directly on the shop floor in close proximity to the probe and without the need for a protective room.

SDI Butler utilizes 2 twin-shell EAF batteries to produce up to 3 million tons of high quality flat roll steel annually. SDI's motivation for the project was an internal aim to improve operational safety and to reduce transformation cost. Tenova's NextGen ${ }^{\circledR}$ System was selected because it's multipoint, full spectrum off-gas analysis capability provides the most complete process control and water detection solution while maintaining minimum required hardware \& maintenance.

Tenova Goodfellow's NextGen® system was commissioned at SDI Butler IN in 2017 to demonstrate NextGen® capabilities and to improve performance of the EAFs while increasing safety via the NextGen® water detection algorithm by detecting the presence of humidity in the EAF that is not considered a normal part of the furnace operation (i.e. abnormal water events). The initial results include reduction of electrical consumption by $3.3 \%$ per ton liquid steel, and an overall reduction of $2.2 \%$ per ton liquid steel. In addition the system has shown capabilities of detecting water leaks in several occurrences on both Batteries.

\section{MATERIAL AND METHODS}

SDI Butler uses two twin-shell batteries ( $4 \times 175$ ton EAF shells) to produce up to 3 million tons of high quality flat rolled steel annually. Although, a single multipoint NextGen ${ }^{\circledR}$ analyzer had the capability to monitor both batteries, SDI chose a more redundant solution to ensure each EAF battery remains fully independent. Each battery at SDI Butler is equipped with identical set-up as illustrated in Figure 1.

The following systems were installed to satisfy SDI Butler's overall process control and operational safety requirements - refer to Table 1 for specific details:

- Two NextGen ${ }^{\circledR}$ multipoint optical analyzers, one for each twin shell battery. Each multipoint analyzer transmits laser signals of the correct wavelength via fiber optic cable to each sampling station 


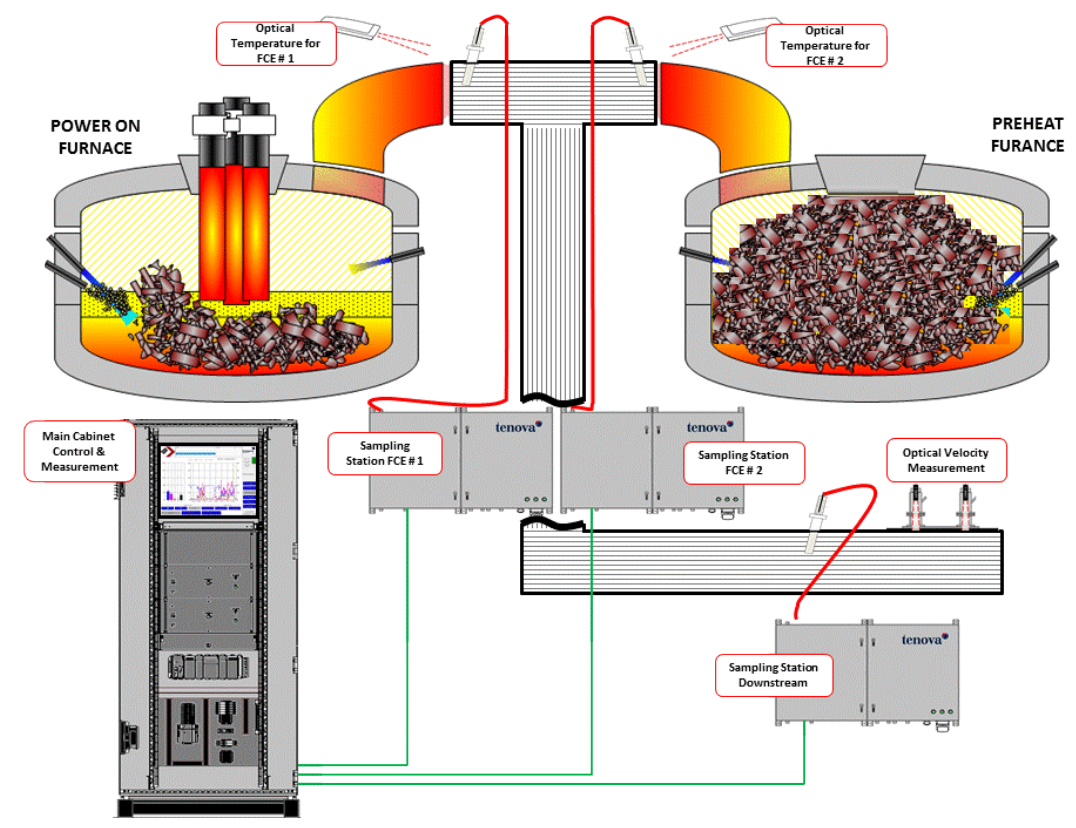

Figure 1: Complete NextGen ${ }^{\circledR}$ System configuration per battery at SDI Butler

- Each battery is equipped with 3 compact off-gas sampling stations to monitor off-gas chemistry at the $4^{\text {th }}$ hole of each EAF shell and at a downstream location. In total, Tenova supplied 6 Sampling Stations. Each sampling station is positioned directly on the shop floor in close proximity to its associated off-gas sampling probe. Each probe is connected to its sampling station by a short heated line. Tenova's patented upstream probes are positioned in the T-duct directly inside the cone of off-gas exiting the furnace thus ensuring continuous analysis of process avoiding any potential of dilution. The sampling stations continuously extract an off-gas sample at high velocity. The off-gas is filtered before passing through the laser cells for complete analysis. The use of high volume, filtered off-gas ensures both fast response and no risk of interrupted laser signals.

- Each battery is also equipped with Tenova's proprietary optical off-gas sensors to measure off-gas temperature ("OTM") and off-gas velocity ("OVM"). The OTM and OVM sensors are designed to provide precise temperature and velocity measurements with minimal maintenance and without the need for consumables. The purpose of these sensors is to improve the control and operation of the fume system, increase safety by monitoring the off-gas conditions down-stream, and better understand overall furnace performance.

- Tenova is providing its Holistic Optimization Technology including optimization and dynamic control of each battery's burners, lances, injectors and fume system suction. It is worth noting that the hardware installed at SDI Butler makes the system i EAF technology ready. Tenova's i EAF ${ }^{\circledR}$ Module \#2 software utilizes the system's full spectrum off-gas analysis, off-gas velocity \& temperature measurements and the SCADA PLC link to provide all the operating data needed to close a Mass \& Energy Balance in real-time which will enable second-by-second dynamic optimized control of both the chemical energy \& electrical energy inputs based on the amount of "net" energy actually received by the charge after allowance for real-time energy losses. ${ }^{[12]}$ 
- Tenova will also provide its Water Detection Technology which uses both continuous $\mathrm{H}_{2}$ \& $\mathrm{H}_{2} \mathrm{O}$ vapor analysis to detect and alarm abnormal water levels in the EAF.

- The system's downstream analysis will also be used to detect and alarm whenever there are abnormally high levels of uncombusted $\mathrm{CO}$ and $\mathrm{H}_{2}$ in the fume system past the combustion chamber.

Table 1: NextGen ${ }^{\circledR}$ implementation - scope of supply for SDI Butler project

\begin{tabular}{|c|c|}
\hline DELIVERABLES for 2 Batteries & ITEMS \\
\hline \multicolumn{2}{|l|}{ HARDWARE } \\
\hline $\begin{array}{l}\text { Multipoint Optical Analyzer - } \\
3 \text { off-gas sampling channels per analyzer }\end{array}$ & $\begin{array}{l}2 \text { Analyzers in Total } \\
1 \text { independent Multipoint Analyzer for each Battery }\end{array}$ \\
\hline Continuous Off-Gas Analysis & $\mathrm{CO}, \mathrm{CO}_{2}, \mathrm{O}_{2}, \mathrm{H}_{2}, \mathrm{H}_{2} \mathrm{O}$ vapor \& $\mathrm{N}_{2}$ by difference \\
\hline $\begin{array}{l}\text { Off-Gas Sampling Stations - } \\
\text { continuously extracts, cleans \& laser analyzes off- } \\
\text { gas sample }\end{array}$ & $\begin{array}{l}6 \text { Sampling Stations in Total } \\
1 @ \text { each EAF shell } 4^{\text {th }} \text { hole location } \\
1 \text { downstream on each Battery }\end{array}$ \\
\hline Probes \& Heated Lines & $\begin{array}{l}1 \text { @ each EAF } 4^{\text {th }} \text { Hole Location } \\
1 @ \text { each Downstream Locations }\end{array}$ \\
\hline Off-Gas Optical Velocity Sensor & 2 in Total; 1 per Battery \\
\hline Off-Gas Optical Temperature Sensor & 4 in Total; 2 per Battery \\
\hline \multicolumn{2}{|l|}{ SOFTWARE \& OPTIMIZATION } \\
\hline Water Detection & $3^{\text {rd }}$ Generation Water Detection Software \\
\hline Process Optimization & $\begin{array}{l}\text { SCADA \& Level } 1 / 2 \text { interface \& dynamic control } \\
\text { functions }\end{array}$ \\
\hline \multicolumn{2}{|l|}{ Dynamic Closed Loop Control } \\
\hline Burners & Optimized Dynamic Control \\
\hline Lances & Optimized Dynamic Control \\
\hline Injectors & Optimized Dynamic Control \\
\hline Fume System Suction & Optimized Dynamic Control \\
\hline \multirow[t]{2}{*}{ Static Optimization } & Charge Bucket Materials \\
\hline & Electrical Set Points \\
\hline
\end{tabular}

\section{NEXT GENERATION OFF-GAS ANALYSIS TECHNOLOGY: A HYBRID EXTRACTIVE - LASER SOLUTION}

NextGen ${ }^{\circledR}$ combines the exceptional start-to-end of heat reliability of extractive technology by using a high volume pump and filters to continuously extract and clean the gas prior to analysis together with the multipoint, response and calibration advantages of laser technology. By selecting the best of both technologies in the field of off-gas analysis, Tenova's NextGen ${ }^{\circledR}$ System has been developed specifically to be compact, reliable and responsive, while providing a full spectrum off-gas analysis for maximum process control \& water detection functionality with less hardware and lower installation \& maintenance costs. Refer to Appendix A for more information on traditional extractive and insitu laser off-gas systems. The SDI Butler management team's objectives were to secure a compact, reliable, fully functional, low maintenance and responsive off-gas system while at the same time maintaining the installation cost as low as possible. After an extensive review of its off-gas 
technology options, SDI management decided that the NextGen ${ }^{\circledR}$ System off-gas analysis system best met all of the criteria as shown below.

Reliability - Positive extraction using a high volume pump remains the very best way to ensure high system reliability and to avoid lost analytical signals. Tenova's NextGen ${ }^{\circledR}$ system uses off-gas extraction through a patented probe positioned directly in the cone of off-gas exiting the EAF at the $4^{\text {th }}$ hole. The probe contains a redesigned primary filter that eliminates water vapor condensation. It requires minimal maintenance and has a life guarantee of 1 year.

Compact - The sampling station (i.e. extractive unit) is mounted directly on the melt shop floor without the need for an environmentally protective room and is connected to the probe with a short heated line. Each station contains a high volume pump, secondary filters and proprietary laser \& analytical cells. Each station is connected to the central multipoint optical analyzer by fiber and coax cables. For SDI, system compactness was an important feature due to the current melt shop layout and strict space restrictions.

Fast Analytical Response \& Uninterrupted Laser Signals - The compactness \& close proximity of the sampling station to the redesigned probe together with active high volume suction dramatically shorten the system's analytical response delay. Analytical response time of NextGen ${ }^{\circledR}$ from probe tip to analysis is $\sim 8$ seconds or less which is between 4 to 5 times shorter than the typical response time of traditional extractive methods and only slightly longer than the 2 seconds quoted for an in-situ laser system. Using clean, filtered off-gas also minimizes the laser cell maintenance and ensures that there is no risk of analytical signal interruptions from start-to-end of the heat which would not be the case with the insitu laser method.

Full Spectrum/Multipoint Analysis - Each sampling station is connected to the central multipoint optical analyzer located in the batteries EAF control room. This unit contains the physical lasers and sends light of the correct wavelength to the analytical cells in each sampling station. The signals from the analytical cells are continuously analyzed to provide a full-spectrum off-gas chemistry. At SDI, each battery's multipoint Optical Analyzer is connected to the battery's 3 independent Sampling Stations thereby minimizing hardware requirements, decreasing system complexity, reducing system maintenance and lowering overall equipment and installation cost. In addition, the full spectrum off-gas analysis ensures full process control and water detection functionality with no compromises.

Operator Safety Improvement - The NextGen ${ }^{\circledR}$ System also offers significantly improved operator safety since the sampling stations are mounted directly on the shop floor under the canopy hood and there is no off-gas physically at the central analyzer. This removes all concerns of a possible $\mathrm{CO}$ leak in a confined space. The net benefit was lower installation cost for SDI and no hazardous concerns during the unit operation.

Future Expandability - The NextGen ${ }^{\circledR}$ Systems full spectrum analysis combined with the OVM \& OTM off-gas sensors and SCADA PLC link will enable SDI Butler to expand the system capabilities in future to include Tenova's i EAF ${ }^{\circledR}$ Module \#2 software which closes a mass \& energy balance in real-time for dynamic optimized control of both the chemical energy \& electrical energy based on the amount of "net" energy actually received by the charge after allowing for real-time energy losses. 


\section{COMPONENTS OF THE NEXTGEN® SYSTEM}

i) Patented Water Cooled Probe \& Heated Element - The NextGen ${ }^{\circledR}$ System's patented probe is unique in the industry being the only design to survive the harsh environment and the intense conditions at the combustion gap. The probe is a proven technology with over $90 \mathrm{EFSOP}^{\circledR}$ installations worldwide in different types of operations. Probe life routinely exceeds its one year guarantee. Because of the high productivity operation at SDI Butler, the NextGen ${ }^{\circledR}$ probe is designed to operate reliably with only $\sim 15$ minutes of routine maintenance to clean the barrel \& internal filter once every 2 weeks during the plant's regularly scheduled shutdown. The upstream $4^{\text {th }}$ hole probe is mounted through an access port in the D1 water-cooled elbow of the EAF (Figure 3). Tenova Goodfellow engineers have extensive experience with almost every possible furnace configuration to ensure successful probe positioning directly within the furnace off-gas cone to ensure accurate furnace off-gas analysis without the effect of dilution air entering at the gap. The downstream probe is mounted in the water cooled duct following the combustion chamber (Figure 2).

Both upstream ( $4^{\text {th }}$ Hole) and downstream (after combustion chamber) probes are equipped with a heated element and a high temperature primary filter to clean the gas of particulate and to eliminate the possibility of water vapor condensation inside the probe to ensure accurate off-gas $\mathrm{H}_{2} \mathrm{O}$ vapor analysis under all operating conditions.

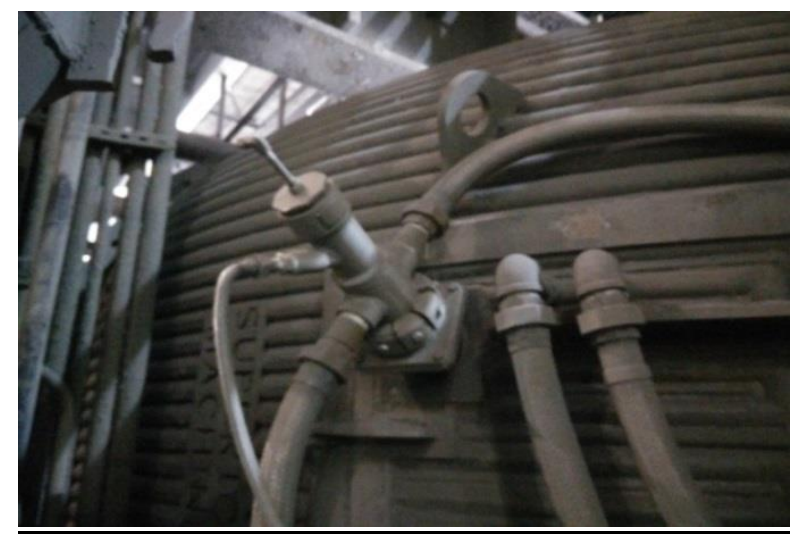

Figure 2: Down-stream Probe Location at SDI

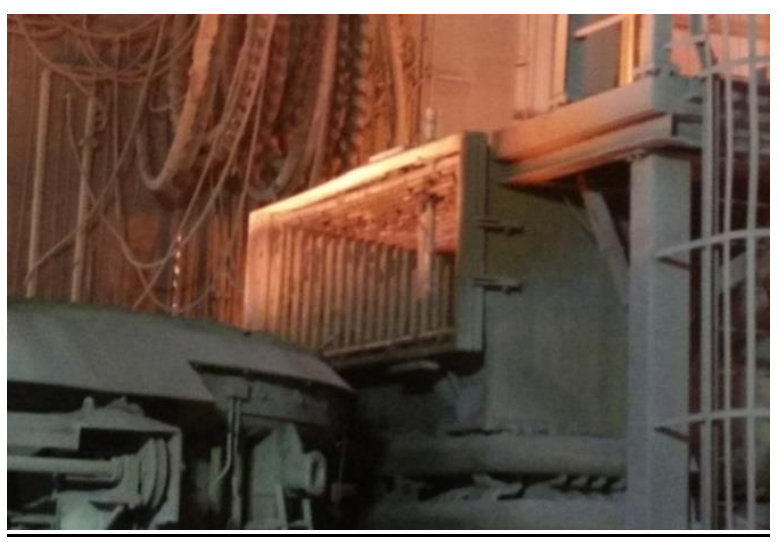

Figure 3: $4^{\text {th }}$ Hole Probe Location at SDI

ii) Heated Line(s) - The off-gas sample is drawn from the probe to the rapid response sampling station through a short protected heated sample line using a high volume pump. The temperature of the heated lines is automatically controlled above the gas dew point to eliminate the possibility of water vapor condensation prior to analysis. The length of the heated lines is short by design to minimize the distance between the compact sampling station and the probe thereby ensuring that the overall response of the system.

iii) Sampling Stations: The sampling station is designed to ensure continuous off-gas analysis during power-on and pre-heating periods. The system's PLC link enables an automatic high pressure nitrogen back-purge for a short period when no process measurements are required. The sampling station is custom designed and proprietary to Tenova Goodfellow - it has many unique features that streamline the design and ensure reliability. The sampling station is located directly on the shop floor, and does not require any 
controlled environment room. The connections to the unit include nitrogen for purging, heated sample lines, power and fiber/coax/Ethernet to the battery's single central multipoint optical analyzer.

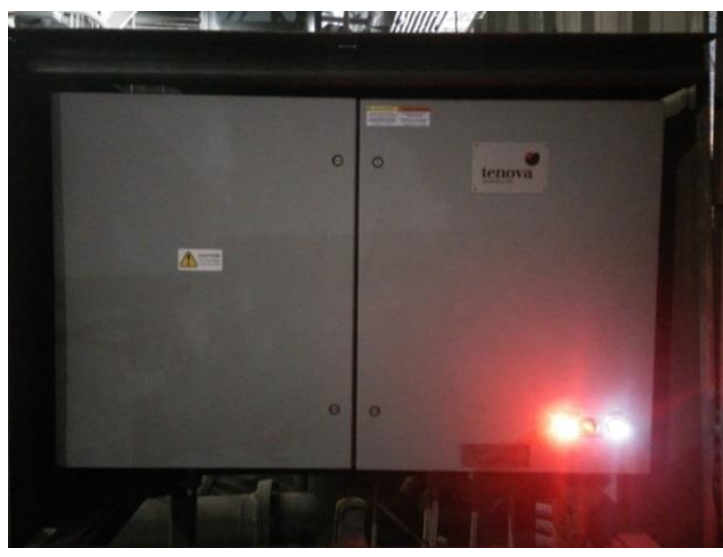

Figure 4: Sampling Station Installed at SDI

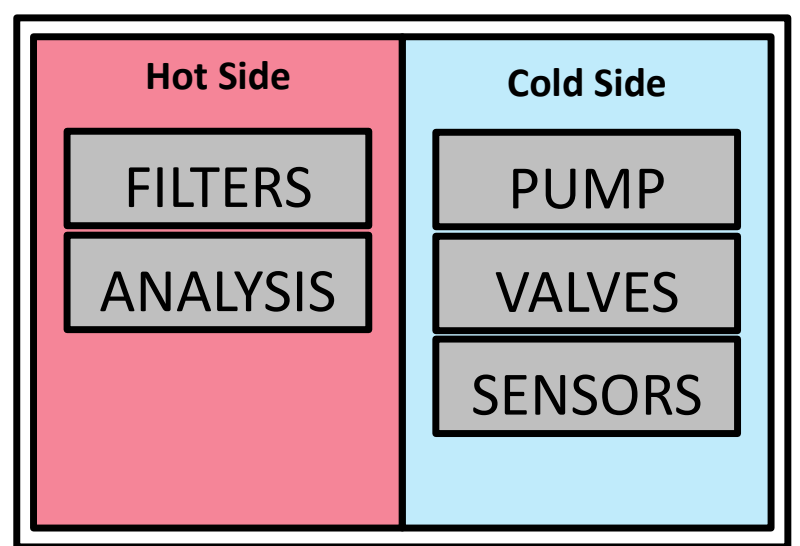

Figure 5: Main Sampling Station Components

iv) Central Multipoint Optical Analyzer - Each battery uses a single multipoint optical analyzer which includes a PLC for controlling each of the sampling stations via Ethernet. The unit is compact, modular and can be tailor designed with multiple lasers based on the off-gas analysis requirements. At SDI, the central analyzer is located in each battery's EAF control pulpit - the units are located up to 100 meters away from the sampling stations without issue. The analyzer's laser system does not require a manual calibration check or the use of specialized calibration gases. The unit is interfaced with the SDI PLC Level 1 to synchronize each sampling station's operation with the EAF operation cycle for sampling, purging or idling if the EAF is down for extended period of time. Figure 7 shows the HMI display for SDI installation, allowing for quick charting of data and smart \& easy troubleshooting of the system.

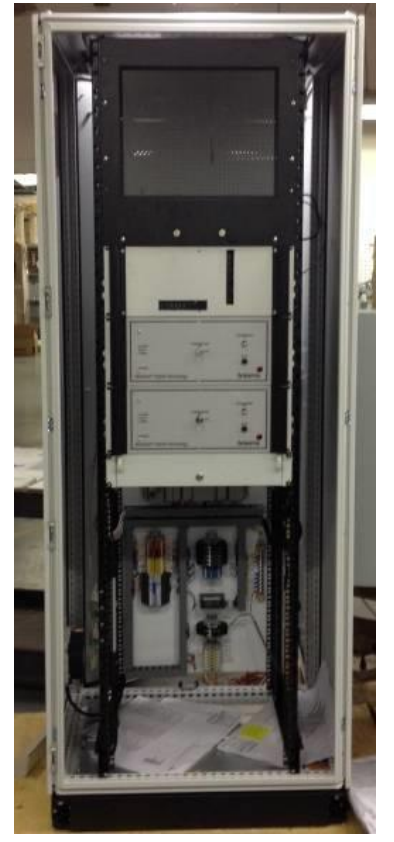

Figure 6: Analyzer Cabinet

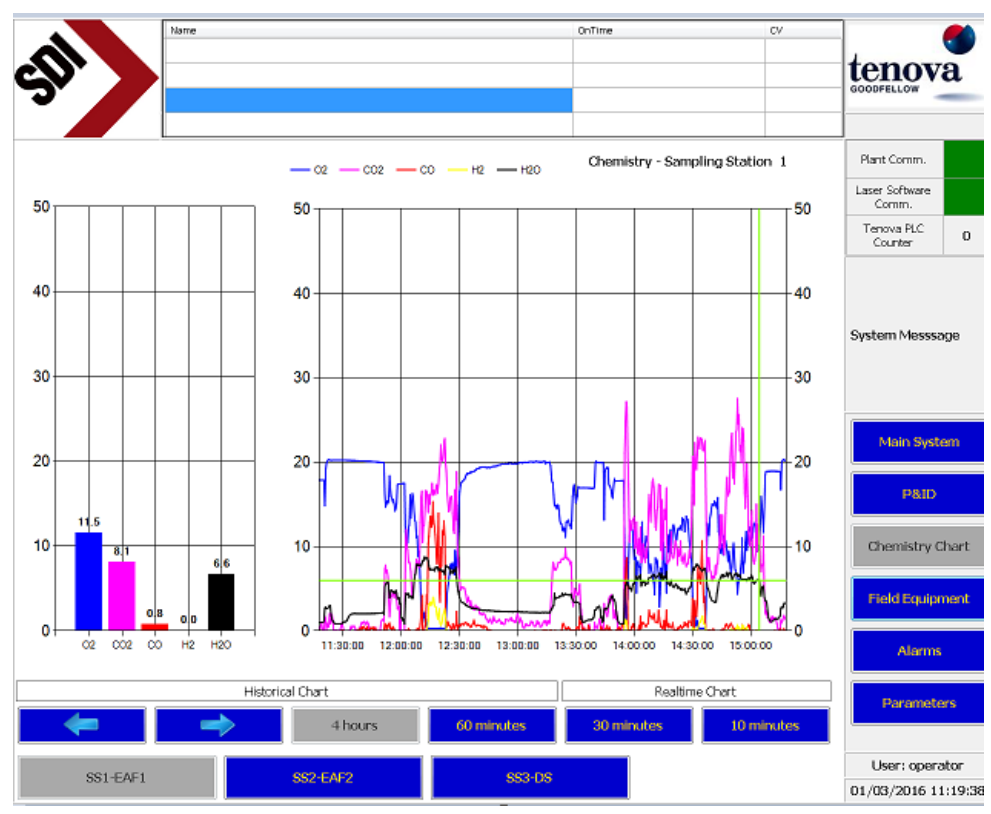

Figure 7: Central Analyzer HMI Screenshot 
v) Optical Velocity Measurement (OVM): The optical velocity measurement (OVM) developed by Tenova Goodfellow is used for continuous measurement of gas velocities in dust-bearing high temperature gases. The temperature of the gases needs to exceed $700^{\circ} \mathrm{C}$ for proper system operation. The OVM system installed at SDI Butler is being used to monitor the off-gas velocity and to calculate the mass flow rate of the off-gas thought different stages of the furnace operation. It is a passive non-contact sensor with no consumable parts and requires minimal maintenance. Figures 8 and 9 show the general schematic of the system and the installation of the OVM on the SDI Butler's water cooled duct, respectively.

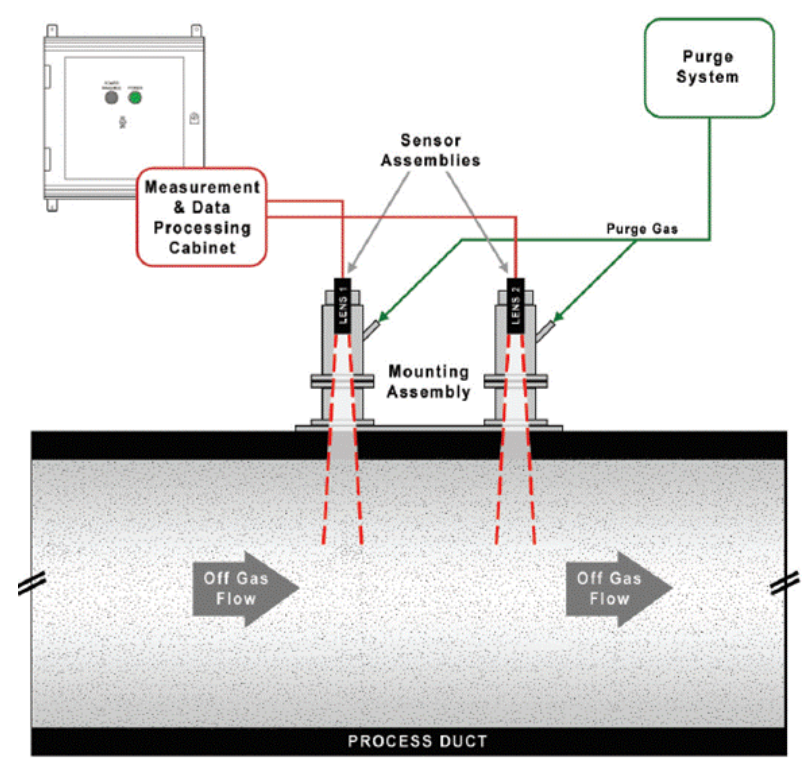

Figure 8: Off-Gas Velocity Measurement

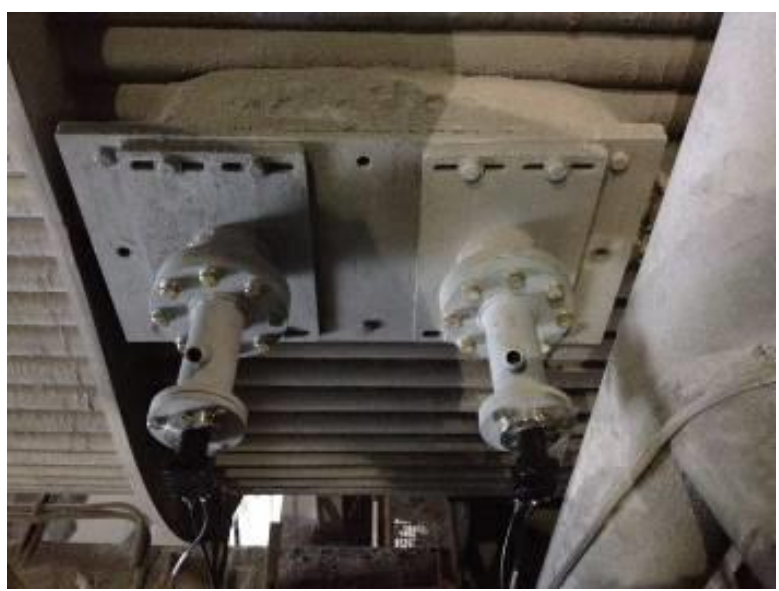

Figure 9: Installation of OVM at SDI

vi) Optical Temperature Measurement (OTM): Each of the furnace shells at SDI Butler is also equipped with a continuous, real-time measurement of off-gas temperature. The OTM system is a passive sensor without consumable parts and requires minimal maintenance. It continuously measures the temperature of clean or dust-bearing gases at temperatures between $700^{\circ} \mathrm{C}$ to $3,000^{\circ} \mathrm{C}$. At SDI, the optical lens and the measurement \& data processing cabinet were installed on top of the pulpit at each battery as shown in Figure 11 below. Because the OTM uses a ratio method for measuring off-gas temperature, the precision of the readings are largely unaffected by dust accumulation on the unit's lens. Each of the units is located far enough from the furnace to ensure safe operation. The temperature measurement is being used during the optimization and water detection portion of the project.

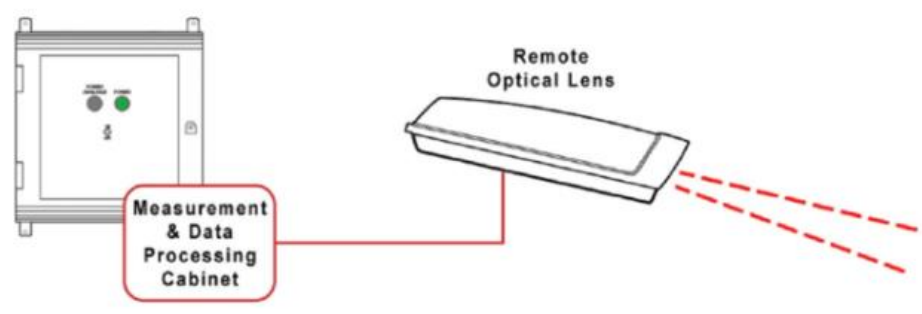

Figure 10: Off-gas Temperature Measurement

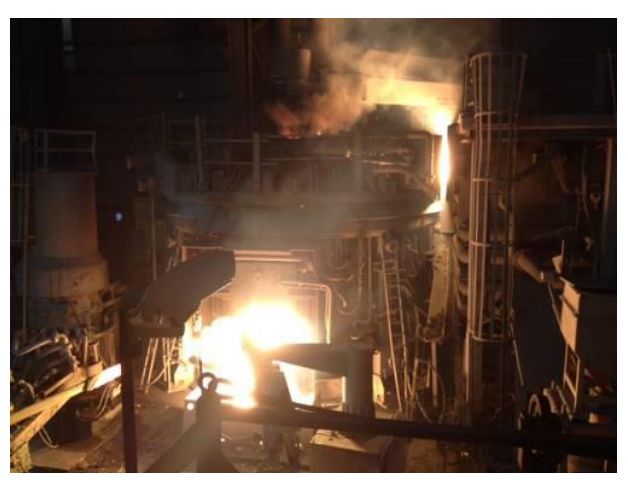

Figure 11: As installed at SDI 


\section{RESULTS}

The commissioned NextGen ${ }^{\circledR}$ System has shown reliable and accurate off-gas measurement for all of the SDI's EAFs at both the upstream and downstream locations. Some of the initial results of the project include improvement in the operating practice resulting in the reduction in the transformation cost per ton liquid steel. In addition the system has also shown the capability to detect water leaks with confirmation of a few real-time water leaks that occurred during the regular production.

\section{System Reliability (Battery \# 1 and Battery \# 2)}

The system has shown a reliable operation while requiring minimal level of routine maintenance. Today, SDI replaces probe filters once every 2 weeks during their scheduled shutdown; however periods as long as 4 weeks without filter replacement has been observed without any measurement interruptions. To date there was not required maintenance on the main cabinet located at the control room. Figure 12 shows the typical analysis of the off-gas at SDI. The analysis indicates measurement of all the gas species $\left(\mathrm{CO}, \mathrm{CO}_{2}, \mathrm{H}_{2}, \mathrm{O}_{2}\right.$ and $\mathrm{H}_{2} \mathrm{O}$ ) for the length of the heat. Pre-heating phase and the Power-on phase of the heat are shown in the Figure 12, allowing for process optimization during the entire heat using the offgas analysis.

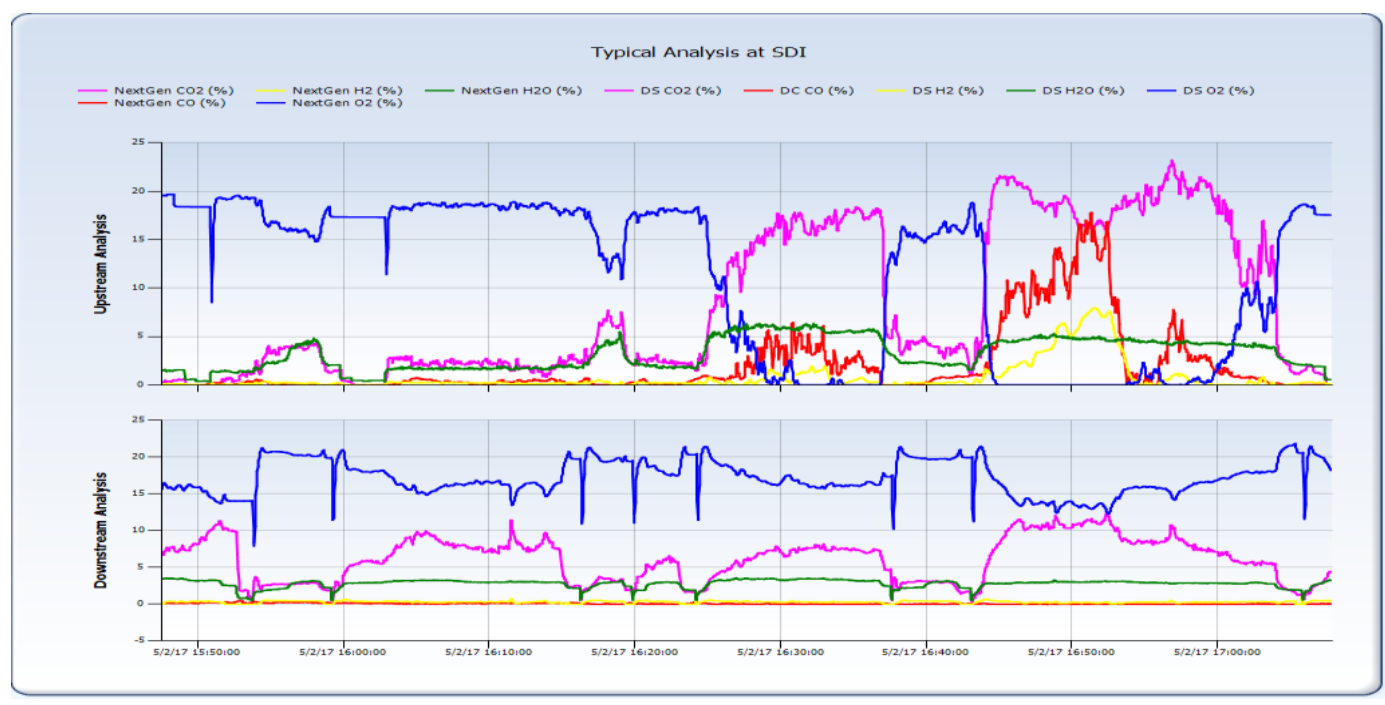

Figure 102: Typical Off-Gas Analysis at SDI

\section{Optimization and Water Detection}

Some initial results from the Phase II have already been demonstrated and accepted by SDI. These results include reduction in transformation cost of $2.2 \%$. Tenova and SDI are working together to improve the process. Implementation of the water detection alarming has been completed on 1 out of the 4 furnaces as well. SDI and Tenova are working together with the goal of completing the project in the $1^{\text {st }}$ quarter of 2017.

i) Optimization Results (Battery \# 1 only)

Initial optimization results of Phase II include an overall cost reduction of $-2.2 \%$ per ton liquid steel. These results have been achieved by improved utilization of the chemical energy during the early stages of the heat. In particular the pre-heating stage has been better 
utilized with improved ratio between the oxygen and gas to create an efficient pre-heating flame.

Table 2: Initial Results at SDI

\begin{tabular}{|c|c|c|c|c|c|c|}
\hline & Electrical (\%) & Oxygen (\%) & Gas (\%) & Inj. Carbon (\%) & Chg. Carbon (\%) & Cost (\%) \\
\hline $\begin{array}{c}\text { Initial Results } \\
\text { (Change compared } \\
\text { to Baseline) }\end{array}$ & $-3.3 \%$ & $2.0 \%$ & $4.2 \%$ & $-6.0 \%$ & $-1.5 \%$ & $-2.2 \%$ \\
\hline
\end{tabular}

In addition, the pre-heat portion has been standardized across all of the operating shifts which has helped to further reduce the electrical consumption, as shown in Table 2 above. The next steps include the implementation of the closed-loop control during the melting phase of the heat, followed by improvement of Carbon/Oxygen balance during the refining phase as well.

\section{ii) Water Detection Results}

Initial results using the water detection system have also been very encouraging with detection of an actual water-leak event on one of the EAF's. The NextGen ${ }^{\circledR}$ System provides both $\mathrm{H}_{2}$ and $\mathrm{H}_{2} \mathrm{O}$ vapor analysis to ensure the highest degree of water leak detection during both reducing \& oxidizing conditions.

In the example below, the system was able to detect the water leak that occurred at the tip of the door lance. The system has been tested using a few months of data showing robustness with very low number of false alarms. Today one of SDl's furnaces uses dynamic threshold for assessing the water leaks and Tenova and SDI are in the process of implementing the exact same detection algorithm on the remaining 3 furnaces.

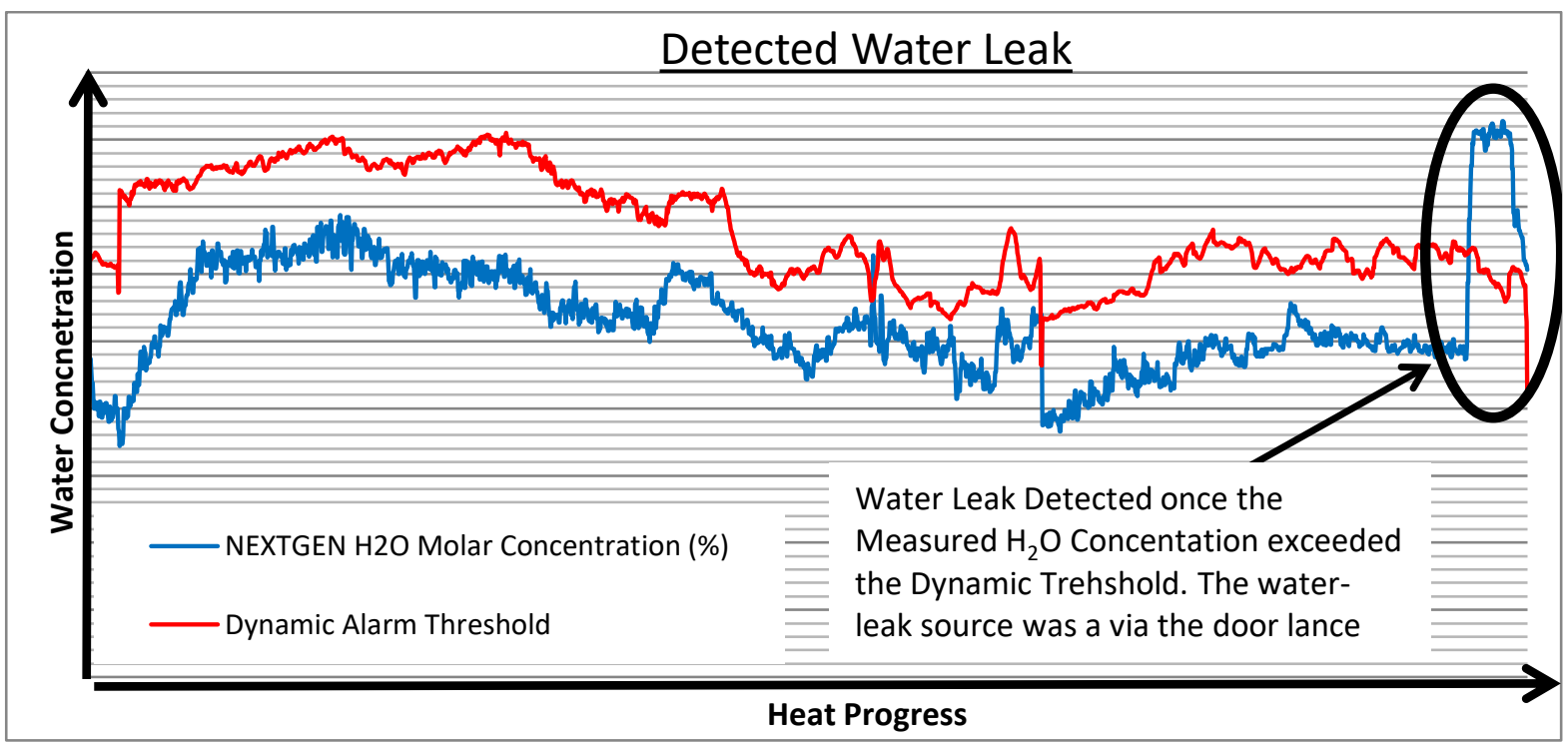

Figure 113: Water Leak Example

Based on the initial results shown for Phase II, SDI and Tenova are excited to show the full potential of the Holistic Process Optimization and the comprehensive water leak detection, already showing promising results. 


\section{CONCLUSION}

Current extractive \& insitu laser analysis methods have pros \& cons including analytical limitations and issues with reliability, calibration, installation cost, maintenance and response time. Tenova Goodfellow has now developed a patent pending next generation multipoint; hybrid off-gas analysis technology trademarked NextGen ${ }^{\circledR}$ that combines the best features of extractive and laser methods. By providing a fast response, high reliability and a complete analysis spectrum, NextGen ${ }^{\circledR}$ is designed to maximize process control, cost savings and safety without compromises. SDI Butler was the first steel plant worldwide to purchase the NextGen ${ }^{\circledR}$ system because it provided a compact solution with substantially reduced analytical hardware, reduced maintenance and without the need for a conventional extractive analyzer room which was important given the shop's floor space limitations.

Furthermore, the NextGen ${ }^{\circledR}$ continuous suction and use of filtered clean gas for laser analysis ensures high reliability, continuous and accurate off-gas analysis from start-to-end of the heat without the risk of signal interruption as with in-situ laser systems. As reported in this paper, SDI has accepted the NextGen ${ }^{\circledR}$ system based on the reliability demonstrated on the project. Also Tenova has shown great initial results of the project, by demonstrating reduction in consumption of $2.2 \%$ for one of the batteries and successful detection of a real water leak event using an advanced detection algorithm.

\section{REFERENCES}

1. S. Schilt, F.K. Tittel and K.P. Petrov, "Diode Laser Spectroscopic Monitoring of Trace Gases", Encyclopedia of Analytical Chemistry, pages 1-29, 2011.

2. S.C. Jepson, US Patent 6748004.

3. H.D. Goodfellow, "Dynamic Process Control and Optimization for EAF Steelmakers", MPT International, Nov. 2006.

4. D.J. Zuliani, H.D. Goodfellow and M. Bianchi Ferri, "EFSOP Holistic Optimization of Electric Arc Furnaces - Past, Present and Future", $9^{\text {th }}$ European Electric Steelmaking Conference, May 19-21 2008, Krakow, Poland

5. D. Vensel and M. Khan, "EAF Performance Improvement at Nucor Steel Auburn using Goodfellow EFSOP”, AISTech Conference Proceedings, 2006.

6. M. Missio, N. Boin, and M. Khan, "Optimization Results at Ferriere Nord using EFSOP Technology, AISTech Conference Proceedings, 2010.

7. M. Khan. S. Mistry, V. Scipolo and S. Waterfall, "Next Generation EAF Optimization at ArcelorMittal Dofasco Inc.", AISTech Conference Proceedings, 2013.

8. W.A. Von Drasek, K.A Mulderink and O. Marin, US Patent 6943886.

9. D.J. Zuliani, V. Scipolo, M. Khan, O. Negru and W. Bilski, "Real-time Water detection in EAF Steelmaking", Iron \& Steel Technology, January, 2014, pages 84-95.

10. M. Khan, S. Mistry and V. Scipolo, "Next Generation EAF Optimization at ArcelorMittal Dofasco Inc.", AISTech Conference Proceedings, 2013. 